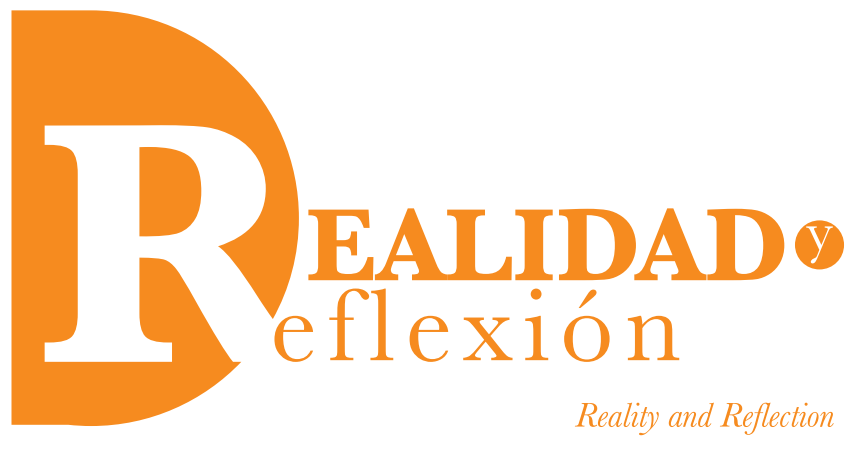

ISSN $1992-6510$

Año 14, No $39, \quad$ San Salvador, El Salvador, Centroamérica

Year 14, $N^{\circ} 39, \quad$ San Salvador, El Salvador, Central America

Revista Semestral

EnERO-JUNIO 2014

SEMESTRAL JOURNAL

JANUARY-JUNE 2014

\title{
Algunas consideraciones sobre la hermenéutica
}

Some reflections on Hermeneutics

\author{
Luis Armando González \\ Licenciado en Filosofía por la UCA. \\ Maestro en Ciencias Sociales por la FLACSO-México. \\ Director Nacional de Formación Continua, \\ Ministerio de Educación. \\ luisgest@gmail.com
}

\section{RESUMEN.}

Este ensayo tiene como objetivo ofrecer una visión global de la hermenéutica como disciplina filosófica. Su intención es criticar a quienes, partiendo de criterios de interpretativos del sentido común, creen que a un texto se le puede dar cualquier significado en el presente, sin respetar lo que su autor quiso decir en su tiempo. La tesis que se defiende es que para interpretar correctamente un texto debe partirse, ante todo, de la comprensión de su literalidad, la cual debe situarse en su contexto literario e histórico correspondiente. HERMENÉUTICA, FILOSOFÍA MODERNA, POSTMODERNISMO.

\section{ABSTRACT}

This essay is focused to a global vision of the hermeneutics as a philosophical discipline. Its intention is to criticize to those who, starting off of criteria of interpretation of the common sense, thinks that to a text any meaning in the present can be given him, without respecting what his author meant in his time. The thesis that defends is that to interpret a text correctly it must be divided, first of all, of the understanding of their text literally, which must be located in its corresponding literary and historical context. HERMENEUTICS, MODERN PHYLOSOPHY, POSTMODERNISM. 
Lahermenéuticaseocupadelainterpretación de textos. Es una disciplina filosófica de gran utilidad práctica por los criterios que ofrece para la comprensión de prácticas sociales, identidades y cosmovisiones, a partir de documentos en los que, mediante símbolos particulares -que pueden ser definidos como un lenguaje-, individuos y grupos las plasman (Gadamer, et. al, 2004). Se ofrece aquí una caracterización general y básica de la hermenéutica, a efecto de ayudar a corregir algunos equívocos que se suelen suscitar en torno a este importante campo del conocimiento filosófico.

\section{La preocupación hermenéutica}

Para comenzar, se tiene que apuntar la preocupación a la que responde la hermenéutica: cómo individuos y grupos de una época (o de una circunstancia histórica particular) pueden comprender las prácticas sociales y formas de ver la vida de individuos y grupos que vivieron en otras circunstancias, en el pasado, y a los cuales no se puede preguntar directamente ni observar en sus prácticas y formas de ver la vida. Es decir, la hermenéutica tiene una preocupación por el pasado y por cómo, desde el presente, se puede comprender a quienes lo vivieron y forjaron su vida en el mismo, pues de ese modo se estaría conociendo su realidad histórica particular y se estarían extrayendo lecciones para el propio presente.

En la hermenéutica hay una aceptación de que el lenguaje es lo que mejor expresa el espíritu de un pueblo. $\mathrm{Y}$ si se quiere conocer el sentido de la vida que tuvo ese pueblo, su cosmovisión, sus hábitos y costumbres, su lenguaje es el mejor medio para ello: el lenguaje que ese pueblo usó en sus diversas manifestaciones: poéticas, filosóficas, religiosas, míticas, pictográficas, ideográficas, icónicas, etc. "Cuando el lenguaje se explicita como tal -escribe Hans-Georg Gadamer-, aparece como la mediación primaria del acceso al mundo. Así se clarifica el carácter irrebasable del esquema lingüístico del mundo. El mito de la autocerteza, que en su forma apodíctica pasó a ser el origen y la justificación de toda validez, y el ideal de fundamentación última que se disputan el apriorismo y el empirismo, pierde su credibilidad ente la prioridad e ineludibilidad del sistema de lenguaje que articula toda conciencia y todo saber" (Gadamer, 1992, p. 327).

El registro de ese lenguaje es, pues, esencial para la hermenéutica: son los textos en los cuales se basa la interpretación hermenéutica. Porque hermenéutica es justamente interpretación de textos. Pero no se trata de cualquier interpretación -es decir, de una interpretación arbitrariapor parte de quien tiene ante sí un texto determinado, sino de una que intenta, ante todo y principalmente, comprender lo que individuos y grupos de otra época quisieron decir en ellos a unos interlocutores determinados. El interés hermenéutico es conocer a los otros, no imponerles la visión de su interlocutor inmediato o de un interlocutor futuro, al cual los autores originales no conocieron y para los cuales seguramente no escribieron lo que escribieron.

No se trata de lo que el intérprete, arbitrariamente, crea qué dicen los textos, sino de un procedimiento (hermenéutico) que busca reducir al máximo la arbitrariedad interpretativa, de tal modo que el intérprete no ponga en el texto significados producto 
de su imaginación y ajenos a lo que sus redactores quisieron poner. Es equivocado pensar que en hermenéutica toda interpretación es legítima, o que interpretar (hermenéuticamente) consista en cambiar libremente, según el parecer, vivencias o creencias del lector, el significado de un texto en una de sus partes o en su globalidad.

Precisamente, contra esta práctica "interpretativa" es que se alza la hermenéutica, ya que de esa práctica se suelen derivar tergiversaciones y manoseos de lo que otros supuestamente dijeron o creyeron, sacando consecuencias distintas e incluso opuestas a las de los redactores originales. En la hermenéutica, interpretar no es cambiar arbitrariamente el sentido y el significado de un texto, sino comprender en la medida de lo posible su significado y sentido originales, para luego actualizarlos de modo tal que digan algo nuevo -algo que sus redactores originales seguramente hubieran dicho- a quienes lo leen en el presente.

El gran riesgo de las interpretaciones posteriores es que el lector (el intérprete) imponga sus prejuicios al texto, sin ser consciente de ello, y traicione el sentido original del mismo, con lo cual se priva de poder comprender la experiencia de vida (histórica y social) que el mismo le puede transmitir, y de la cual puede obtener una guía para su propia experiencia de vida. Como Heidegger atinó a ver, "toda interpretación va acompañada de algunas ideas preconcebidas sobre lo que se quiere interpretar" (Viñas Piquer, 207, p. 494), y si estas ideas preconcebidas no se hacen conscientes y si, además, imponen su sentido sobre lo que se quiere interpretar, entonces no es posible una hermenéutica genuina, sino que lo que se tiene es una manipulación del texto. La interpretación hermenéutica, sin dejar de reconocer los prejuicios de quien lee un texto, busca evitar la anulación de lo que quisieron decir quienes lo redactaron: es la "estructura circular de la comprensión".

Sólo una conciencia capaz de replegarse sobre sí misma y con un sentido verdaderamente histórico puede hacer frente a esta situación. $Y$ no precisamente tratando de evitar la influencia de los prejuicios, sino haciéndose cargo de ellos, cargando con ellos. Pues lo importante no es liberarse de las ideas preconcebidas, sino ser consciente de que su presencia resulta inevitable cuando se recoge de manos de la tradición un tema o un objeto de estudio y se pretende continuar la investigación en el punto en el que otros lo han dejado o en cualquier punto que no sea un punto cero. Como señala Paul Ricoeur, 'toda interpretación sitúa al intérprete in medias res y nunca al comienzo o al final', es decir, que 'llegamos, en cierto sentido, exactamente a mitad de una conversación que ya ha comenzado y en la que intentamos orientarnos para poder aportar, cuando nos llegue el turno, nuestra propia contribución' (Viñas Piquer, 207, p. 496).

En el caso de un texto que se interpreta, en esa "conversación" participan tres actores:

a. Los redactores originales del mismo (un individuo o un grupo), que no necesariamente tuvieron que redactarlo de un solo tirón $\mathrm{o}$ en un periodo delimitado de tiempo; 
b. Sus destinatarios directos, es decir, a quienes iba expresamente dirigido o que se las vieron con el mismo en el momento de su redacción (o sea: los contemporáneos de los redactores del texto); y

c. Los lectores del texto de una época posterior, para quienes no iba dirigido y quienes por razones particulares, relativas a sus circunstancias e intereses, se acercan al mismo, con el fin de comprenderlo.

Estos actores “interpretan" el texto: el redactor original, cuando lee y corrige su propia escritura (y se hacen la pregunta: "¿es eso lo que quiero decir con esas palabras?"); el lector-destinatario cuando trata de comprender lo que le quiso decir el redactor (y se pregunta: "¿qué es lo que se me quiere decir con esas palabras?"; y el lector posterior cuando, desde una época distinta, se enfrenta al texto y trata de comprenderlo (y se pregunta: “¿qué significa lo que está escrito en ese texto del pasado?").

Se trata de interpretaciones, por así decirlo, "naturales", inmediatas e inevitables. En las dos primeras, aunque haya incomprensión o una interpretación incorrecta de lo que dice el texto, las correcciones y aclaraciones no son imposibles: al redactor original puedo corregirlo para que exprese mejor (con los recursos lingüísticos que él domina o que otros le pueden sugerir) lo que él quiere decir, y el destinatario inmediato puede pedir al redactor original o a contemporáneos suyos que le aclaren, si hay confusión en el significado del mensaje recibido, qué es lo que se le quiso decir.
$\mathrm{Y}$ el redactor original puede, ante una recepción equívoca de su texto, aclarar qué fue lo que quiso decir, ya sea verbalmente o con otro texto. En realidad, la hermenéutica se preocupa por la tercera interpretación, la que hace el lector posterior; esto es, el intérprete de otra época, el cual sólo cuenta, como fuente casi exclusiva, ${ }^{1}$ con el texto para descifrar lo que sus redactores quisieron decir.

Esta última recepción es la que preocupa a la interpretación hermenéutica, pues este lector posterior puede perder de vista lo que quisieron decir sus redactores originales, imponiéndole significados que le son ajenos y que dependen de sus intereses actuales. En el caso de un texto tan importante como El Corán -de la Biblia y la Torá cabe decir algo semejante, obviamente- las interpretaciones no hermenéuticas es decir, arbitrarias, no históricas, no contextuales, no literarias - dieron lugar ( $y$ dan lugar) a tergiversaciones que derivaron (y derivan) incluso en persecuciones $y$ guerras sangrientas.

\section{II. “Interpretación natural" e "interpretación hermenéutica"}

El lector posterior también hace una interpretación "natural", que consiste en imponer al texto sus propios prejuicios. Esto se hace de manera inmediata e inevitable. Se trata del primer acceso al texto, del cual se deriva una primera interpretación. La interpretación hermenéutica va más allá de esta “interpretación natural”; mientras que ésta es una "interpretación primera", aquélla es una "interpretación segunda", no "natural" ni inmediata ni inevitable. Es un proceder artificial, metódico 
y con pretensiones filosóficas y científicas, destinado a vencer las limitaciones de la “interpretación natural”. Para llegar a esta conclusión acerca del carácter metódico y fundamentado (filosófica y científicamente) de la hermenéutica transcurrió un tiempo bastante largo.

Como anota Gadamer: "la conciencia hermenéutica sólo puede darse bajo determinadas condiciones históricas. La tradición, a cuya esencia pertenece naturalmente el seguir transmitiendo lo transmitido, tiene que haberse vuelto cuestionable para que tome forma la conciencia expresa de la tarea hermenéutica que supone apropiarse de la tradición" (Gadamer, 1977, p.16). Y añade este autor:

La comprensión sólo se convierte en una tarea necesitada de dirección metodológica a partir del momento en que surge la conciencia histórica, que implica una distancia fundamental del presente frente a toda transmisión histórica. La tesis de mi libro es que en toda comprensión de la tradición opera el momento de la historia efectual, y que sigue siendo operante ahí donde se ha afirmado ya la metodología de la moderna ciencia histórica, haciendo de lo que ha devenido históricamente, de lo transmitido por la historia, un 'objeto' que se trata de 'establecer' igual que un dato 'experimental'.

La hermenéutica, en este sentido, nace de la desconfianza en la interpretación espontánea y acrítica -no fundamentada ni metódica - que usualmente se hace de un texto cuando se accede a él con la intención de comprenderlo. Esta "comprensión" se convierte en una "traducción" del texto según "lo que significa para mí"; y, en este marco, es lógico que haya tantas "interpretaciones" como lectores, lo cual no sólo deja abierta las posibilidades de significado que se le puedan atribuir, sino que es prácticamente imposible valorar una como mejor que otras, pues todas son igualmente legítimas una vez que se acepta que cada lector/intérprete es libre de "interpretar" según sus propios deseos e intereses el significado de un texto.

Se entra en el terreno pantanoso del subjetivismo y del relativismo, pero sobre todo se pierde de vista que el texto que se interpreta tuvo un redactor concreto que pretendía decir algo con significado a unos destinatarios también concretos, y que eso impone unos límites a sus posibles interpretaciones posteriores. Esto ofrece un anclaje "objetivo" a todo ejercicio de interpretación de un texto o de una tradición.

Siempre que se lee un texto se le interpreta y quien lo lee lo carga con sus propios intereses y preocupaciones, pero la hermenéutica no trata de esta interpretación subjetiva y voluntarista que deja en manos del lector (intérprete) la libertad de comprender a su manera su significado. A la interpretación hermenéutica le interesa sobremanera conocer el significado que dieron al texto sus redactores originales, porque de ese modo se conoce su visión de mundo, su situación vital, sus valores y costumbres.

Una vez hecho esto, la hermenéutica se interesa por establecer qué significa ese texto para nosotros, para quienes lo leemos e interpretamos en una circunstancia histórica distinta. Son los dos polos de la 
hermenéutica: el texto en su significado original y el texto con el significado que le dan sus lectores en el presente. En la interpretación hermenéutica la prioridad la tiene el primer polo, y sólo desde el primero se debe llegar al segundo, aunque sean situaciones vitales de quienes se ubican en el primero las que desencadenen el proceso de acercamiento al texto.

En la interpretación común (no hermenéutica) que hace cualquier persona cuando lee un texto lo prioritario es el segundo polo, al punto de que muchas veces se llega a anular el segundo. Pero para eso no se requiere de estudio especializado alguno, pues es una propensión normal de los seres humanos contaminar con sus propias valoraciones $y$ preocupaciones aquello que leen.

Es esa propensión -como ya se dijo- la que busca corregir la hermenéutica con sus procedimientos de interpretación de textos, a sabiendas de que es sumamente difícil establecer el significado original de lo que dice un texto, sobre todo cuando ese texto ha sufrido alteraciones en distintas épocas, y de evitar absolutamente que no se los contamine inconscientemente con significados del presente. Además, es claro para la hermenéutica que quienes interpretan un texto del pasado lo hacen desde sus preocupaciones y sus dudas del presente, las cuales deberán ser iluminadas con esa búsqueda que se hace en el pasado.

\section{Centralidad del texto y su contexto}

¿Qué quisieron decir en el texto quienes lo redactaron o quienes fijaron en él determinados símbolos? Nunca se sabrá de manera definitiva. Siempre se tratará de hipótesis, es decir, de conjeturas. En palabras de Umberto Eco: "la iniciativa del lector consiste en formular una conjetura sobre la intentio operis. Esta conjetura debe ser aprobada por el conjunto del texto como un todo orgánico. Esto no significa que sobre un texto se pueda formular una y sólo una conjetura interpretativa. En principio se pueden formular infinitas. Pero, al final, las conjeturas deberán ser probadas sobre la coherencia del texto, y la coherencia textual no podrá sino desaprobar algunas conjeturas aventuradas" (Eco, 2011, p. 28).

Así, pues, la hermenéutica formula hipótesis plausibles al respecto, y para ello su punto de partida son los textos con los que se las ve. En palabras de Gadamer:

Hay que señalar en todo caso que sólo desde el concepto de interpretación aparece el concepto de texto como algo central en la estructura de la lingüisticidad; lo que caracteriza al texto es que sólo se presenta a la comprensión en el contexto de la interpretación y aparece a su luz como una realidad dada. Esto rige incluso en el consenso dialogal, porque las opiniones discutidas se pueden repetir hasta buscar la vía para hacia una formulación vinculante común, un proceso que culmina después en la fijación protocolaria. En un sentido similar indaga el intérprete de un texto lo que hay propiamente en él. Esta indagación podrá tener siempre una respuesta no exenta de prejuicios y parcialidad, pues el que pregunta busca una confirmación directa de sus hipótesis. Pero en esta remisión a lo que hay en el texto, éste aparece como el punto de referencia frente a la cuestionabilidad, arbitrariedad o 
al menos pluralidad de posibilidades interpretativas que apuntan a él.

¿Qué es un texto?² Es un registro de símbolos (con significado), esto es, signos plasmados por individuos $y / 0$ grupos en una superficie que puede ser, por ejemplo, papiro, papel, barro, madera o de forma digital. Un texto no es una superficie o material en limpio (una página en blanco), sino lo que está registrado, en signos, en esa superficie o material. Esos signos (lingüísticos, pictográficos, ideográficos, etc.,) deben formar un sistema que los unifica y les da un significado mayor al que tienen por separado. Son esos signos y la unidad que forman los que deben y quieren ser interpretados por el hermeneuta. Se puede tratar de una unidad de significado que sea parte de una unidad de significado mayor, que se convierte en su contexto, referencia interpretativa obligada, por aquello de que "un texto fuera de su contexto, no es más que un pretexto".

Su supuesto es que esos signos fueron plasmados por individuos humanos (solos o en grupo) que tenían una visión de la vida y que realizaban determinadas prácticas sociales que se expresan, directa o indirectamente, consciente o inconscientemente, en aquéllos. No se asume -salvo los hermeneutas bíblicos, coránicos o de la Torá que son creyentesque son textos de procedencia divina o algo parecido, sino textos humanos que pueden ser comprendidos por seres humanos, en una circunstancia distinta, utilizando el recurso del lenguaje que es el puente entre unos y otros.

Desde la hermenéutica no interesa, asimismo, el texto por el texto (ni mucho menos dotarlo de vida propia, como pretenden algunas figuras del postmodernismo deconstruccionista 3 ), sino los motivos, intereses, visión de mundo y circunstancias de quienes lo redactaron. Tras lo que dice, sugiere, evoca o no dice el texto que se busca aquello que quisieron decir quienes lo redactaron, aquello en lo que ellos pensaron. Y el único o mejor acceso que se tiene a lo que estos quisieron decir y a lo que pensaron es precisamente el texto. Ya que si ellos estuvieran vivos no habría problema en preguntarles qué quisieron decir o pensaron cuando escribieron lo que escribieron: la hermenéutica se aboca al pasado de los pueblos y su acceso a ese pasado son los textos, que son su bien más preciado.

La gran tarea hermenéutica consiste en interpretar esos textos para acceder a ese pasado, pero lo hace desde su presente, y para iluminarlo y comprenderlo mejor: este el círculo hermenéutico propuesto por H.G. Gadamer.

Interpretar un texto, por tanto, consiste en intentar comprender, en una época distinta, lo que quisieron decir en su época quienes lo redactaron (o plasmaron en una superficie determinados símbolos). $O$ sea, uno o varios hablantes-oyentes de una comunidad lingüística del presente intentan comprender lo que dijeron (o quisieron decir) uno o varios hablantes-oyentes de una comunidad lingüística del pasado. ¿Qué quisieron decir en los símbolos que plasmaron (es decir, cuál es el significado de esos símbolos para ellos, en su tiempo)? ¿Qué no quisieron decir? ¿Qué ocultaron? ¿Cuál era su visión de la realidad? ¿Cuáles sus intereses? ${ }^{4}$

Todas estas son preguntas sustantivas (de fondo), y sin respuesta definitiva, sino 
probable, pues el recurso básico con el que se cuenta para responderlas son textos que, muchas veces, sufren de deterioro físico que hace difícil su manejo. También se tienen preguntas de forma: ¿Qué lenguaje utilizaron para hacerlo? ¿En qué estilo lo hicieron? ¿Qué modos de expresión usaron? ¿Qué tipo de simbolismo? ${ }^{5}$

No hay otro camino para llegar al fondo que partir de la forma, de lo plasmado y expresado deun cierto modo, en determinados caracteres pictóricos, lingüísticos, ideográficos, etc., y con un estilo determinado. Y para responder a las preguntas de forma y fondo antes enunciadas son de gran ayuda, de un lado, "la semiótica y la lingüística, que han aportado nuevos conocimientos sobre el modo funcional y la estructura de los sistemas de lenguaje y de los sistemas de signos, y de otro la teoría del conocimiento según la cual el lenguaje nos da a todos el acceso al mundo. Ambas corrientes actúan conjuntamente para hacernos ver desde una nueva óptica los puntos de partida de una justificación filosófica del acceso científico al mundo" (Gadamer, 1992, p. 326).

Entonces el punto de arranque hermenéutico es la realidad inmediata de los textos. En el caso de textos con símbolos lingüísticos, se trata de partir, en primer lugar, de las letras-palabras, y sus relaciones sintácticas y semánticas: es decir, de su literalidad, sin la cual no hay interpretación (hermenéutica) posible.

Quienes redactaron esos textos se valieron de una lengua determinada (la que seguramente hablaban), usaron unas letras-palabras de la misma (relacionadas de una cierta manera, según las normas gramaticales propias de esa lengua, con estilos de escritura y según unos géneros literarios vigentes) porque, como hacemos quienes escribimos textos en el presente, seguramente con las letras- palabras de esa lengua, combinadas de un cierto modo, querían decir lo que querían decir. ¿Qué querían decir? ¿A quién o quienes se lo querían decir? Igual que los redactores de textos en el presente, seguramente distintas cosas y a distintos destinatarios. Quizás querían referirse a realidades de su entorno natural y social; quizás querían hablar de sus emociones y sentimientos, o de sus temores, o de la muerte y sus misterios, o arengar para guerra, o corregir algunas fallas en el comportamiento de los demás, o normar ciertas costumbres y corregir determinados hábitos...

Para cumplir cualquiera de los propósitos anteriores (u otros) se valieron del lenguaje disponible en su tiempo, y que sobrevive en los textos que perduran de aquella época. Es a través de esos textos que se puede acceder no sin dificultades a eso que sus creadores querían decir y también a quienes lo querían decir, y cuál fue la forma que eligieron para hacerlo.

Eso es lo que pretende indagar la hermenéutica, siendo la primera vía de acceso -no la única- la literalidad de la que escribieron. Y se trata de la primera vía de acceso porque es lo que "materialmente" conecta al intérprete del presente con los redactores del pasado. No es la única vía a lo que estos quisieron decir porque no siempre eso que quisieron decir, como sucede a quienes redactan textos en el presente, tuvo un significado literal, que es el significado básico de una palabra en un sistema lingüístico determinado. 


\section{Sintaxis, semántica y pragmática}

Junto a la Sintaxis y la Semántica, la Pragmática forma la tríada en la que se basa la teoría semiótica del lenguaje propuesta por Charles Morris en 1938. Si la Semántica se ocupa de las relaciones entre el signo y el referente expresado, la Sintaxis de las relaciones que mantienen los signos entre sí, la Pragmática estudia las 'relaciones que mantienen el emisor, el receptor, el signo y el contexto de comunicación' (...). Según Teun A. Van Dijk, 'la Pragmática es aquella parte del estudio del lenguaje que centra su atención en la acción’ (...). Afirma además este autor que es 'esencial para la acción (...) el hecho que responda a una intención, particularmente por parte de la persona que lleva a cabo el hecho' (Viñas Piquer, 1997, p. 508).

Como saben los lingüistas y los semiólogos (y lo estableció Ferdinand de Saussure ${ }^{6}$ ), las lenguas forman un sistema sintáctico y semántico, y en ese sistema las palabras tienen un significado que viene dado por su pertenencia al mismo, de tal modo que situados en una época determinada y habiendo identificado el sistema lingüístico vigente en esa época (para una sociedad o grupo de sociedades) se puede establecer el significado básico (literal) de una palabra usada -y relacionada con otras de una cierta manera- en esa época.

Así las cosas, como la hermenéutica cuenta como recurso básico con textos, su primera tarea, además de validarlos y datarlos (usando, por ejemplo, procedimientos químicos) consiste en fijar su literalidad. Esto exige establecer la gramática básica del texto, identificando las letras-palabras y su relación sintáctica y semántica, a modo de lograr una primera interpretación de carácter literal. O sea: establecer lo que literalmente quisieron decir, en su época, quienes redactaron el texto.

Sobre la importancia de lo literal, Umberto Eco apunta lo siguiente, que es ciertamente aleccionador:

Hay que empezar todo discurso sobre la libertad de la interpretación con una defensa del sentido literal. Hace unos años, el presidente norteamericano Reagan, probando los micrófonos antes de una conferencia de prensa, dijo más o menos: «Dentro de pocos minutos daré la orden de bombardear Rusia». Si los textos dicen algo, ese texto decía exactamente que el enunciador, en un breve espacio de tiempo subsiguiente a la enunciación, habría ordenado el lanzamiento de misiles con ojivas atómicas contra el territorio de la Unión Soviética. Apremiado por los periodistas, Reagan admitió luego haber bromeado: había dicho esa frase pero no quería decir lo que significaba... Mi opinión es que, para interpretar la historia de Reagan, aunque sea en su versión narrativa, y para estar autorizados a extrapolar todos los sentidos posibles, es necesario ante todo captar el hecho de que el presidente de los Estados Unidos dijo - gramaticalmente hablando - que tenía la intención de bombardear la URSS. Si no se comprende esto, ni siquiera se comprendería que (no teniendo la intención de hacerlo, por admisión propia) hubiera bromeado. 
Admito que este principio puede sonar, si no conservador, por lo menos trivial, pero no tengo la menor intención de renunciar a él. Y sobre esta firme intención se desarrolla hoy gran parte del debate sobre el sentido, sobre la pluralidad de los sentidos, sobre la libertad del intérprete, sobre la naturaleza del texto, en una palabra, sobre la naturaleza de la semiosis (Eco, 2011, pp. 18-19).

Lo literal es un punto de partida ineludible en la hermenéutica; es como el primer peldaño de una escalera que poco a poco se irá subiendo hasta llegar a una mejor interpretación de lo que, presuntamente, quisieron decir quienes elaboraron originalmente los textos sometidos a consideración. La dimensión sintáctica y semántica del lenguaje es clave, pero insuficiente.

Su dimensión pragmática es fundamental para comprender el significado de las palabras; y es que el significado (semántica) de las palabras no sólo depende de su relación (sintáctica) con otras, sino que también depende de su uso por una comunidad de hablantes-oyentes: ¿Cómo eran usadas las palabras (o símbolos) plasmados en el texto sometido a escrutinio? ¿Cuál era el significado derivado de ese uso?

Esta pregunta introduce el tema de las variaciones de significado de una palabra, de su connotación, lo cual está más allá (pero no es independiente) de su literalidad. Es decir, en el pasado como en el presente cuando un individuo (o un grupo, pues puede haber textos colectivos) redacta un texto lo hace como miembro de una comunidad lingüística, usa palabras vigentes (usadas y conocidas) en el sistema de lenguaje de esa u otra comunidad, pues lo hace para comunicarse (hacerse entender) por quienes lo rodean.

Son esas palabras vigentes y usadas las que en sí mismas y/o relacionadas de una cierta manera con otras denotan y connotan determinados significados, los cuales son de interés hermenéutico. La denotación y la connotación de las palabras no se pueden establecer si no se parte de su literalidad. Y mientras que la denotación de una palabra en un sistema lingüístico determinado está muy cerca de su literalidad, la connotación nos lanza más allá de esa literalidad, sin que la misma se pierda: es la literalidad de tal o cual palabra, usada de una cierta manera y en relación con otras, la que connota aquel significado (o aquellos significados) que busca quien la utiliza.

\section{El género literario}

¿Cómo saber, cuando se lee un texto y se lo quiere interpretar correctamente, si el significado de las palabras usadas por sus redactores era literal (si eso pretendían al usarlas) o si querían connotar otras cosas, es decir, si les estaban dando un significado que iba más allá de lo literal? Y es que en las distintas lenguas hay palabras de una fuerte carga connotativa en sí mismas (como en español las palabras "alma", "diablo", "amor"), en tanto que hay otras con mayor peso denotativo (como en español las palabras "cobre", "plomo", "química” o “sociología”).

De unas y otras se puede establecer su literalidad, siendo posible que quienes las usaran pretendieran comunicar a sus destinatarios el significado básico otorgado a 
esas palabras en el sistema lingüístico de su época. ¿Y si no era así? ¿Y si lo que querían era transmitir otros significados?

Responder esto es complicado para los hermeneutas. Para ello usan un recurso que se ha mostrado de gran utilidad interpretativa: la ubicación de un determinado texto en cualquiera de los géneros literarios de cuyo uso se tiene evidencia desde tiempos antiguos 7 . Es decir, cuando una persona, del presente o del pasado, redacta un texto lo hace con un estilo que expresa y sitúa en un determinado contexto su intención: puede ser una carta, una homilía, un discurso apocalíptico, una oración fúnebre, un poema, un ensayo filosófico, un tratado científico o un panfleto político.

Identificar el género literario al que pertenece un texto es clave para interpretar lo que quisieron decir quienes los escribieron y a quienes iba dirigido; ese género literario permite acercarse al significado que ellos dieron a las palabras (o símbolos) usadas, a la articulación de esas palabras con otras para formar las oraciones, y luego estructurar el texto de una forma particular, ya sea solo o integrado a un texto más amplio.

Los géneros literarios surgen y se desarrollan históricamente; no son un patrimonio con el que se encuentran los creadores en cada época (intelectuales, poetas, periodistas, científicos, narradores, etc.), sino los individuos comunes y corrientes que, aunque no lo sean conscientes de ello, cuando redactan un texto se ciñen a uno o varios géneros literarios vigentes en su tiempo.

Con el paso del tiempo, a los géneros literarios clásicos (la lírica, la épica o narrativa y la dramática) -de larga data en la historia de la humanidad- se añadieron el género epistolar, el género homilético, el género sapiencial, el género novelístico, el género periodístico, el género ensayístico, el género biográfico, entre otros. Identificar el género literario de un texto ayuda, primero, a agruparlo junto con otros de las misma características de forma y contenido; también, en segundo lugar, para enmarcar (encuadrar) las posibles intenciones de quien lo escribió, así como sus destinatarios; $y$, en tercer lugar, para establecer, con razonabilidad, el significado de las palabras usadas, sus frases y oraciones.

El género literario usado, ahora como en el pasado, es una camisa de fuerza para lo que se quiere y se puede decir. Es un contexto de significado del texto en su conjunto así como de las partes que lo constituyen. El intérprete de un texto no puede dejar de lado el género literario en el que el mismo está redactado porque esto le ayudará a determinar el significado de lo que en el mismo se dice.

De este modo, hay géneros literarios que fuerzan, ante todo, hacia la literalidad de las palabras, frases y oraciones que lo forman. Los textos castrenses, por ejemplo los partes militares en lo que se describe un plan de ataque o los resultados de un combate, están redactados -por quienes lo hacencon la finalidad de que sus destinatarios comprendan lo más "objetivamente" posible una situación que no pueden ver con sus propios ojos.

Este "género literario" (el de los informes narrativos) fuerza a quienes redactan textos de esa naturaleza al uso de palabras, frases y oraciones directas, simples y lo más neutrales posibles, de modo que 
sus destinatarios lo entiendan sin mayor dificultad interpretativa. Un intérprete posterior (un hermeneuta), si sabe ubicar un texto del pasado, en este género narrativo podrá comprender, ateniéndose a la literalidad de lo que ahí se dice, cuál era el significado más probable del texto. Por supuesto que un parte militar puede estar escrito en lenguaje cifrado, en clave o con palabras que traicionan la literalidad del sistema de la lengua que se está usando. Pero ese lenguaje cifrado o con palabras que traicionan el significado establecido no es arbitrario, sigue ciertas reglas, que son conocidas por sus destinatarios...y que un intérprete posterior puede también conocer.

Un ejemplo, ciertamente burlesco, del uso del lenguaje castrense (neutro, directo, descriptivo) para referirse a situaciones nada castrenses aparece en la novela de Mario Vargas Llosa Pantaleón y las visitadoras. Otros ejemplos son los de situaciones de guerra en las cuales uno de los bandos en pugna puede decidir reducir las cifras de sus bajas y aumentar las del bando opuesto, y establecer la regla de que siempre que se sufran "100" bajas se escribirá en los informes "10", y que cuando se causen "10" bajas al enemigo se escribirá en los partes de guerra "100". De todos modos, en unos casos como en otros, la fuerza de lo escrito recae en la literalidad de lo que se dice, aunque sea una verdad a medias o una mentira absoluta.

En segundo lugar, relacionado con lo anterior, hay géneros literarios que fuerzan más hacia la denotación y menos hacia la connotación. Es el caso del género literario que se puede denominar "informe o tratado científico". Por lo menos desde los griegos, en el siglo $\mathrm{V}$ antes Cristo, este género se ha venido abriendo paso, siendo sumamente potente en la actualidad. Uno de los desvelos de sus cultivadores, de quienes desde tiempos atrás han hecho ciencia, ha sido fijar en las palabras adecuadas el conocimiento obtenido de la elaboración de hipótesis y su contraste con la experiencia. Se han preocupado porque sus textos estén elaborados con palabras que no sean plurisignificativas, es decir, que no sean demasiado connotativas.

La purificación del lenguaje científico en algunos momentos llegó al extremo de pretender hacer de la lógica y la matemática el lenguaje exclusivo de la ciencia, para que todos entendieran lo mismo cuando se abordara un tema científico.

Ante esta imposibilidad, hay un consenso firme en las comunidades científicas de que, además de usar palabras que no carguen con múltiples significados, lo pertinente es establecer definiciones de los términos usados y ser coherente con esa definición a lo largo del texto que se redacta. Entonces, si se establece que un texto del pasado (que se quiere interpretar en el presente) pertenece al género literario "tratado científico" es razonable atender al significado denotativo que, en la lengua usada por los redactores en su época, tenían las palabras que tejen el texto.

Y es que lo más seguro es que ese género literario les impusiera, como les sucede a quienes lo hacen en el presente, un uso de las palabras que privilegiaba su significado denotativo, el cual incluso pudo haber sido fijado en una definición. Es obvio que entre más lejos del presente esté un texto "científico", mayor será la diferencia del significado denotativo de las palabras usadas en él respecto de las palabras 
equivalentes usadas en el presente. Pero se tiene que hacer el esfuerzo hermenéutico por encontrar aquel significado, y relacionarlo con el nuestro para establecer cambios y continuidades. Es anacrónico anular el significado de una palabra del pasado, y remplazarlo por el que esa palabra tiene en el presente. Los intérpretes comunes (los no hermeneutas) suelen hacer eso permanentemente.

El género literario "ético-normativo" tiene características muy parecidas al género anterior. Tienen una carga fuertemente denotativa, pero no porque se refieran a algo del entorno (para describirlo) sino porque dictan normas de conductas prácticas guiadas por un deber ser. Sus redactores, en el pasado como ahora, buscan influir en los comportamientos de sus lectores para que dirijan en una cierta dirección.

Y para ello, estos deben entender con facilidad lo que se les dice, no se trata de unas palabras, frases u oraciones para la reflexión, sino para la acción. En la justificación para dictar tales o cuales normas podrán aparecer palabras cargadas de connotación -como "por la furia de los dioses", "por el poder de Zeus" o "por la fuerza del Espíritu"-; pero la problemática social que se quiere atender y la orientación de conducta que se propone (que se norma) se suelen plantear en fórmulas de lenguaje que no dejan lugar a equívocos para sus destinatarios directos y primeros intérpretes: "no matarás" (o sea no asesinarás a tu semejante, tuyo), "no robarás" (o sea no arrebatarás sus bienes, esposa, hijos y animales a tu semejante), etc.

Un intérprete (hermeneuta) del presente puede, si cuenta con los recursos textuales suficientes, determinar si el género literario en el que se ubica el texto que examina es ético-normativo, y a partir de eso tener una base bastante firme como para establecer el significado de las palabras-frases-oraciones usadas en el mismo. Por el género literario, el hermeneuta podrá suponer, con razón, que la literalidad y la carga denotativa seguramente son predominantes en las formulaciones que identifican problemas y que quieren influir en los comportamientos de los destinatarios. Si el hermeneuta quiere iluminar los problemas y las prácticas del presente con el texto examinado, no puede obviar el significado literal y denotativo que los autores originales dieron, en su tiempo, a sus formulaciones.

No puede, pues, asignarle significados arbitrariamente, arguyendo que cuando las palabras fueron usadas originalmente los autores les otorgaron una variedad de significados y sus destinatarios directos igualmente las interpretaron de una y mil maneras. Es cierto: una persona puede interpretar de mil maneras un mensaje y quien lo transmite puede pretender eso, pero en otras (muchas) ocasiones quien transmite un mensaje quiere que se entienda de una determinada manera y quien lo recibe, aunque no quiere, se ve forzado a hacerlo. El género literario usado marca la pauta para una u otra cosa.

Mientras que, en tercer lugar, hay géneros literarios que se inclinan fuertemente por el uso de un lenguaje connotativo. La novela suele moverse esta dirección. Pero es la poética la que lleva hasta sus últimas consecuencias el uso de palabras cargadas de significados diversos o de palabras que significan algo distinto a su significado literal (y denotativo) en virtud del juego que se hace con ellas al relacionarlas con otras. 
Como señala Umberto Eco, en la metáfora los signos no se refieren al mundo real o a mundos posibles, sino a otros signos, en un ejercicio de invención que incluso puede ser accidental. Técnicamente, Eco plantea el tema de la metáfora del siguiente modo:

La metáfora no instituye una relación de similitud entre los referentes, sino de identidad sémica entre los contenidos de las expresiones, y sólo indirectamente puede concernir a la manera en que consideramos los referentes. Los intentos de aplicar a la metáfora una lógica formal de los valores de verdad no explican su mecanismo semiótico (...). Si la sustitución metafórica concerniera a una relación cualquiera entre objetos del mundo, no podríamos comprender el Cantar de los cantares cuando recita

Tus dientes son como un rebaño de ovejas que sale del baño, o Eliot (The Waste Land,1, 84) cuando dice:

I will show you fear in a handful of dust. La sonrisa de una bella muchacha no resulta similar en nada a un rebaño de ovejas balantes y mojadas, y resultaría difícil decir en qué sentido el miedo que siento o puedo haber sentido se parece a un puñado de polvo. La interpretación metafórica trabaja sobre interpretantes (...), es decir, sobre funciones sígnicas que describen el contenido de otras funciones sígnicas. Es obvio que los dientes no son blancos en el sentido en que las ovejas son blancas, pero es suficiente que la cultura interprete ambos a través del predicado expresado por la palabra blanco para que la metáfora pueda trabajar sobre una similitud. Se trata de similitud entre propiedades de dos sememas, no de similitud empírica (Eco, 2011, pp. 96-97).

La poética es el género literario de las metáforas y, en consecuencia, el ámbito de las connotaciones y del juego de plurisignificados de las palabras. Sus sonidos, todo lo que evocan y convocan, todo lo que pueden añadir a otras palabras al juntarse con ellas... esto es lo propio de la poesía. Y los cultivadores (autores/ lectores) de este género literario saben bien que en un texto poético no se buscan definiciones de la realidad o respeto a la literalidad y denotación de las palabras, sino sonidos, ritmos y emociones: es decir una experiencia estética.

Hay que decir, por último, que los géneros literarios mencionados (y otros) no necesariamente se den en estado puro. Es decir, puede suceder que se den mezclas de ellos, como sucede en eso que algunos denominan "género epistolar", es decir, el tipo de escritura que se registra en las cartas privadas/personales, o en las cartas que se remiten a destinatarios colectivos (de lo cual hay abundantes ejemplos en el Nuevo Testamento). El género epistolar tiene una estructura literaria propia, pero se pueden integrar en él textos poéticos, exhortaciones e información analítica o teórica (como hacían, por ejemplo, Karl Marx y Friedrich Engels en su tiempo), de modo que la parte esencial del género -su naturaleza de comunicación de asuntos personales, familiares e íntimos, fuertemente emotivos y sentimentales-, sirve de motivo para dar pie a la comunicación/transmisión de 
otros asuntos, que asimismo disminuyen su carga de rigor y seriedad (que seguramente tendrían en su propio contexto).

Una importante tarea hermenéutica, en este sentido, consiste no sólo en identificar el género literario de un texto, sino en identificar su posible pertenencia a un contexto en el que están presentes otros textos que pertenecen a otros géneros literarios, cuyo conjunto (como macrotexto) se convierte también en un desafío interpretativo de carácter hermenéutico. Uno de los macrotextos más complejos para la interpretación hermenéutica es la Biblia, en la cual, además de procesos de redacción en los que intervinieron distintos redactores en distintas épocas, están presentes prácticamente todos los géneros literarios clásicos.

\section{Reflexión final}

La hermenéutica, como disciplina filosófica, trata de asegurar una correcta comprensión de los textos. Correcta quiere decir metódica y fundamentada en criterios científicos y filosóficos. Quien sigue criterios hermenéuticos cuando se enfrenta a un texto, al igual que un intérprete común, va animado por la siguiente pregunta: ¿Qué me quiere decirel textoenmiactual circunstancia histórica? Hay quienes, equivocadamente, creen que la hermenéutica avala que quien se hace esa pregunta, responda: "El texto me quiere decir todo lo que yo quiera, pues el interpretar es libre $y$, por tanto, es legítimo que yo lo interprete a mi manera, otra persona lo haga de manera distinta, y así sucesivamente". Definitivamente, la hermenéutica no avala este proceder, aunque sí reconoce que es una actitud interpretativa natural, que no está destinada a comprender el pasado ni lo que pensaron e hicieron quienes vivieron en ese pasado. Asimismo, mientras que el intérprete común impone al texto, con toda naturalidad, significados que dependen de sus prejuicios -es decir, lo interpreta arbitrariamente- para que aquél le diga aquello que a él le interesa, quien sigue criterios hermenéuticos, pese a hacerse la misma pregunta y verse impulsado a imponer sus prejuicios al texto, asume como un primer desafío -previo a la respuesta por lo que el texto le dice a él en su época- la comprensión de lo que el texto dijo en su tiempo a sus destinatarios y a sus contemporáneos. Y eso lleva a la indagación del sistema de lenguaje en el que inscribe el texto (su estructura sintáctica y semántica, su pragmática y el género literario al que pertenece), para sostener con el mayor rigor posible las hipótesis acerca de lo que sus redactores presumiblemente quisieron decir, a través del texto, en su época particular.

Sólo cuando se ha fijado con el mayor rigor posible el significado original del texto, está justificado desde la hermenéutica responder a la pregunta por lo que ese texto nos dice en el presente. Es decir, no se puede atribuir legítimamente, en el presente, un significado de un texto del pasado si no se comprende de la mejor manera posible lo que en el mismo se quiso decir cuando se redactó y la forma en la que se dijo. La interpretación avalada por la hermenéutica filosófica es la que nace de la comprensión del texto en su contexto y como una creación simbólica que comunica una forma de ver la vida situada y fechada históricamente.

Artículo recibido: 19 de mayo de 2014. Artículo aprobado: 6 de junio de 2014. 


\section{Notas y referencias}

1 Fuente casi exclusiva, porque pueden ser accesibles otros recursos históricos (urbanísticos, arquitectónicos, arqueológicos, etc.), que ayuden a la interpretación de un texto y a entender (y a ubicarlo en) su contexto histórico.

2 En tres de las acepciones del Diccionario del español actual (de Manuel Seco, Olimpia Andrés y Gabino Ramos) "texto" significa: a) "enunciado escrito", b) "escrito considerado en su redacción original y auténtica”; y c) "conjunto de signos, o enunciado, oral o escrito, considerado como objeto de estudio".

3 Es severa la crítica que hace Mario Vargas Llosa de quienes "han relativizado las nociones de verdad y de valor hasta volverlas ficciones, entronizando como axioma que todas las culturas se equivalen y disociando la literatura de la realidad, confinando aquella en un mundo autónomo de textos que se remiten a otros textos sin relacionarse jamás con la experiencia humana" (Vargas Llosa, 2001, p. 84)

4 A lo anterior se añaden las siguientes interrogantes: ¿Cuáles son los intereses de quienes los leen en el presente? ¿Cuál es su visión de la realidad? ¿Son compatibles los intereses y visiones de la realidad de unos y otros?

5 De esas interrogantes son inseparables estas: ¿Es un lenguaje semejante al nuestro (los intérpretes)? ¿El simbolismo tiene significados equivalentes a los de nuestros símbolos? El estilo empleado y las formas de expresión ¿se usan en la actualidad? ¿Son las mismas? ¿Cuáles son las posibles equivalencias de símbolos y significados?

6 Según Seassure - dice David Viñas Piquer- la lengua es un sistema de relaciones y oposiciones, es decir, los elementos de un sistema se hallan interrelacionados y se definen por oposición: cada elemento es lo que otros no son".
7 Dice el Diccionario del español actual del género literario: "grupo o clase a la pertenece una obra literaria o artística, con arreglo a criterios de forma y contenido establecidos por la tradición".

\section{Bibliografía}

Armstrong, K. (2007). Historia de la Biblia. Barcelona: Debate.

Dilthey, W. (1980). Introducción a las ciencias del espíritu. Madrid: Alianza.

Eco, U. (2011). Los límites de la interpretación. http://es.scribd.com/ doc/55504851/Eco-Umberto-Los-limites-de-la-interpretacion.

Gadamer, H.G. 1977). Verdad y método (I). Salamanca: Sígueme

Gadamer, H.G. (1992).Verdad y método (II). Salamanca: Sígueme.

Gadamer, et. al, (2004). Diccionario de hermenéutica. Bilbao: Universidad de Deusto.

Lawrence, B. (2007). Historia del Corán. Barcelona: Debate.

Vargas Llosa, M. (2001). “Postmodernismo y frivolidad”. En El lenguaje de la pasión. Madrid: Aguilar,

Viñas Piquer, D. (2007). Historia de la crítica literaria. Barcelona: Ariel.

Seco M., Ramos, G., Andrés, O. (1991). Diccionario del español actual. Madrid: Aguilar. 